Rezorpsiyon

tedavisinde indirekt

ultrasonik aktivasyon

ile MTA kullanımı: Üç

olgu sunumu

\section{Resorption treatment using MTA with indirect ultrasonic activation: Three case reports}

\author{
Arş. Gör. Dt. Şeyma Şentürk \\ Marmara Üniversitesi Dişhekimliği Fakültesi, \\ Endodonti A.D., İstanbul
}

Yrd. Doç. Dr. Fatıma Betül Baştürk Marmara Üniversitesi Dişhekimliği Fakültesi, Endodonti A.D., İstanbul

Yrd. Doç. Dr. Dilek Türkaydın

Marmara Üniversitesi Dişhekimliği Fakültesi, Endodonti A.D., İstanbul

Prof. Dr. Hesna Sazak Öveçoğlu

Marmara Üniversitesi Dişhekimliği Fakültesi, Endodonti A.D., istanbul

Prof. Dr. Mahir Günday

Marmara Üniversitesi Dişhekimliği Fakültesi, Endodonti A.D., İstanbul

Geliş Tarihi: 12.07.2016

Kabul Tarihi: 21.08.2016

DOI: 10.5505/yeditepe.2016.53824

\section{Yazısma Adresi:}

Yrd. Doç. Dr. Fatıma Betül Baştürk

Marmara Üniversitesi Dişhekimliği Fakültesi, Endodonti A.D., Başıbüyük Yerleşkesi, Maltepe, İstanbul

Tel: 02164211621

E-posta: fatimabasturk@gmail.com

\section{ÖZET}

Rezorpsiyon kemik, dentin ve sementin geri dönüşlü veya geri dönüşsüz kaybına sebep olan bir süreçtir. İnternal ve eksternal rezorpsiyonların tamirinde Mineral Trioksit Agregat (MTA) kullanımı yaygınlaşmaktadır. MTA ile kanal dolumu çeşitli yöntemlerle yapılmaktadır. İndirekt ultrasonik aktivasyon, MTA'nın boşluklara daha iyi dolmasını sağlayan bir metottur. Bu vaka raporunun amacı internal ve eksternal rezorpsiyon vakalarının indirekt ultrasonik aktivasyon kullanılarak MTA ile tamirinin incelenmesidir.

Anahtar kelimeler: İndirekt ultrasonik aktivasyon, MTA, perforasyon, rezorpsiyon.

\section{SUMMARY}

Resorption is a process that leads to cement, dentine and bone loss and can be reversible or irreversible. Mineral Trioxide Aggregate (MTA) has been successfully used as an obturation material in both internal and external resorption cases. There are various placement techniques for MTA. Indirect ultrasonic activation is the method of choice for cases in which fill density is an important factor. The aim of this report is to present internal and external resorption cases which were repaired with MTA using indirect ultrasonic activation.

Key words: Indirect ultrasonic activation, MTA, perforation, resorption.

\section{GíRiş}

Rezorpsiyon osteoklast veya sementoklast hücrelerinin aktivitesi sonucu dentin, sement ve kemik kaybıyla karakterize bir klinik süreçtir. ${ }^{1}$ Patolojik rezorpsiyon hiçbir zaman kendiliğinden oluşmaz. Rezorpsiyonu başlatan etken travma, nekrotik dokular ve bakteriyel kaynaklı enfeksiyon ya da kist tümör gibi oluşumların veya yanlış ortodontik kuvvetlerin periodontal ligamente baskısı olabilir. ${ }^{2}$ Rezorpsiyonun çeşidine göre uygulanması gereken tedavi prosedürleri de farklılık gösterir. Travmaya bağıı bazı geçici rezorpsiyonlar iyi bir takiple düzelebileceği gibi yine travma kaynaklı oluşan bir yer değiştirme rezorpsiyonu multidisipliner bir tedavi gerektirebilir. $^{3}$

Tüm rezorpsiyon türlerinin tedavisinde endodontik müdahale gerekli değildir. Örneğin hafif bir travma sonucu oluşan yüzey rezorpsiyonu etken ortadan kaldırıldığında kendiliğinden gerileme gösterir. ${ }^{4}$ Benzer şekilde, ortodontik kuvvetler sonucu ortaya çıkan rezorpsiyonlarda kuvvet ortadan kalktığında rezorpsiyonun ilerlemesi durur.

Kök kanalındaki nekrotik dokulardan ve bakteriyel enfeksiyondan kaynaklanan rezorpsiyonların tedavisinde ise rutin kanal tedavisi uygulanması yeterlidir. ${ }^{3}$ Internal rezorpsiyonda tüm kök kanalının doldurulabilmesi için sıcak dolum tekniklerinin kullanılması daha yaralıdır., ${ }^{5,6}$ Rezorpsiyonun çeşidine bakılmaksızın periodontal dokular ve pulpa boşluğu arasında bir bağlantı yani perforasyon oluştuğu durumlarda kanal obturasyonunun biyouyumlu bir materyalle yapıl- 
ması gerekmektedir. Bu amaçla genellikle MTA (mineral trioksit agregat) kullanılmaktadır. ${ }^{7}$

Bu vaka raporunda, Marmara Üniversitesi Diş Hekimliği Fakültesi Endodonti Anabilim Dalına başvuran hastalardan rezorpsiyon teşhis edilen ve indirekt ultrasonik aktivasyon metoduyla MTA kullanılarak tedavi edilen üç olgu sunulmaktadır.

\section{OLGU}

Vaka raporlarının tümü Marmara Üniversitesi Diş Hekimliği Fakültesi Endodonti Anabilim Dalı́na başvuran hastalardan hazırlanmıştır. Hastalara planlanan tedavi ve diğer tedavi seçenekleri ile ilgili gerekli bilgiler verildikten sonra hastaların onamı alınmıştır.

\section{OLGU 1}

Kliniğe ağrı ve şişlik şikayetleri ile başvuran 14 yaşındaki hastanın öyküsünde 2 yıl önce geçirilen travma nedeniyle 11 nolu dişin avülse olduğu, dişin reimplante edildiği ancak sonrasında başka bir tedavi uygulanmadığı anlaşılmıştır. Klinik muayenede bukkal mukozada fistül ve dişte artmış mobilite, radyolojik muayenede ise 11 nolu dişte eksternal rezorpsiyon olduğu tespit edilmiştir. Illk seansta kök kanalındaki bakterilerin ve nekrotik dokuların temizlenmesi amacıyla preparasyon yapılmış ve 4 hafta boyunca $\mathrm{Ca}(\mathrm{OH})_{2}$ (kalsiyum hidroksit) ile intrakanal medikasyonu uygulanmıştır. Diş asemptomatik hale geldiğinde ve fistül kapandığında kanal dolumu MTA (ProRoot MTA, Dentsply, Tulsa, OK, USA) ile yapılmıştır. Kanal dolumu sırasında MTA'nın apikalden taşmaması için kollajen bariyer Collaplug (Calcitek, Carlsbad, CA) ile çalışma boyunda bir tıkaç oluşturulmuştur. Daha sonra MTA, kanal içerisine MAP (Micro Apical Placement, Dentsply, Mailefer, Ballaigues, Switzerland) sistem aracılığı ile taşınmış ve kanal içerisine yerleştirilen bir spreader ultrasonik olarak aktive edilmiştir. Bu şekilde MTA'nın apikaldeki bariyeri bozacak bir kuvvetle kondanse edilmesinin önüne geçilmesi hedeflenmiştir. Kanala indirekt ultrasonik aktivasyon ile gönderilen MTA'nın üzerine nemli bir pamuk pelet yerleştirilmiş ve sonrasında apikal kısım Marmara Üniversitesi Diş Hekimliği Fakültesi Ağız, Diş ve Çene Cerrahisi bölümünde kürete edilmiştir (Resim 1).

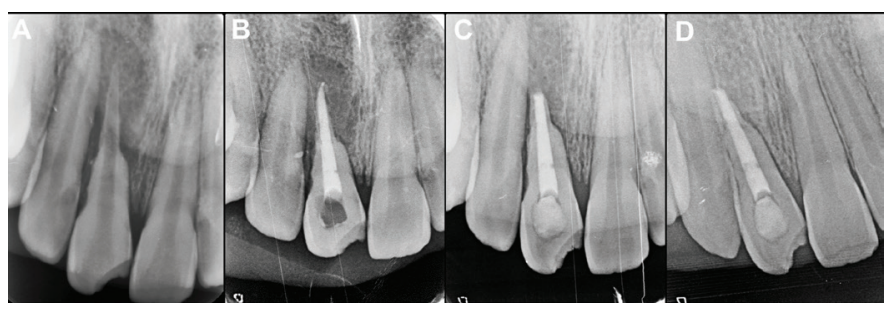

Resim 1: A) Endikasyon röntgeninde yaygın bir eksternal rezorpsiyon hattı izlenmektedir. B) Kanalın indirekt ultrasonik aktivasyon uygulanarak MTA ile doldurulmasından hemen sonraki röntgen görüntüsü C) Altı aylık takip röntgeni $\mathbf{D}$ ) İki senelik takip röntgeni.

\section{OLGU 2}

Herhangi bir şikayeti bulunmayan hastada radyolojik muayene sonucu kanal tedavili 46 numaralı dişinde kronik apikal periodontitis ile birlikte distal kökte rezorpsiyon bulunduğu tespit edilmiştir. Hastanın eski kanal dolgusu söküldükten sonra 1 haftalık $\mathrm{Ca}(\mathrm{OH})_{2}$ ile intrakanal medikasyonu uygulanmıştır. Dişin meziyal kökleri gütaperka ve $\mathrm{AH}$ plus (Dentsply DeTrey, Konstanz, Germany) ile lateral kondensasyon tekniği uygulanarak doldurulmuştur. Distal kökü ise perforasyon alanına kadar indirekt ultrasonik aktivasyon uygulanarak MTA ile doldurulmuştur (Resim 2).

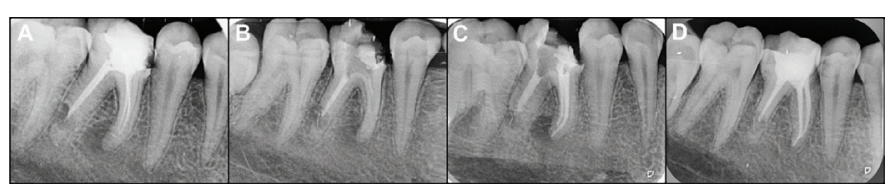

Resim 2: A) Endikasyon röntgeninde meziyal kanalda yaygın br eksternal rezorpsiyon hattı izlenmektedir. B) Kanalların sökülmesinden hemen sonra meziyal kanalın MTA ile dolumunun röntgen görüntüsü. Meziyal kanal dolgusundan bir parça güta perka koparak apikalde kalmıştır. C) Altı aylık takip röntgeni D) Iki senelik takip röntgeni.

\section{OLGU 3}

Estetik problemden dolayı fakültemize başvuran hastanın 21 nolu dişinde radyolojik muayene sonucu internal rezorpsiyon bulunduğu tespit edilmiştir. Tedavinin ilk seansında kanal genişletme, şekillendirme ve dezenfeksiyon prosedürleri uygulandıktan sonra intarakanal medikamenti olarak $\mathrm{Ca}(\mathrm{OH})_{2}$ kullanılmıştır. Kanaldan gelen kanamanın durmaması rezorpsiyon alanında periodontal dokulara perforasyon olabileceğini düşündürdüğü için tüm kanal indirekt ultrasonik aktivasyon uygulanarak MTA ile doldurulmuştur (Resim 3).

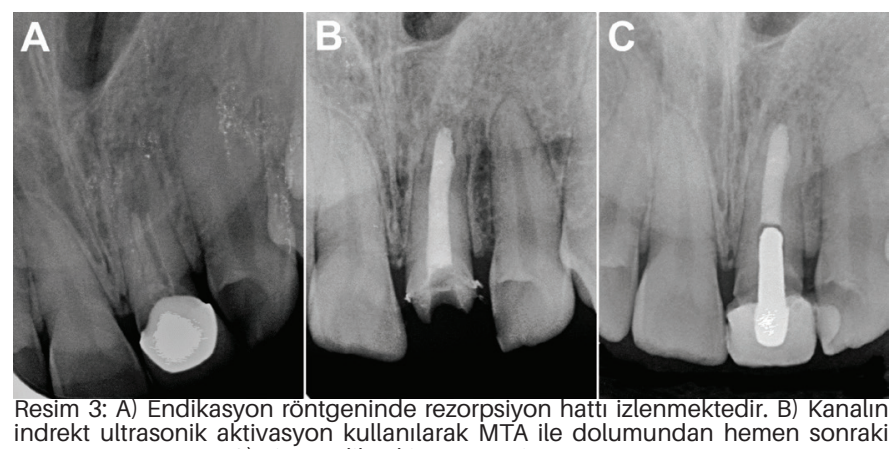
röntgen görüntüsü. C) Bir senelik takip röntgeni.

\section{TARTIŞMA}

Kök rezorpsiyonunu başlatan en yaygın etken pulpal dokulardaki enfeksiyondur. Presementum ya da predentinin yaralanmasını takiben enfekte dentin tübülleri yoluyla etkilenen pulpal ve periapikal dokularda osteoklastik aktivitenin başlamasıyla rezorpsiyon oluşur. Klinik olarak rezorpsiyonun ilk aşamalarında genellikle dişler asemptomatiktir ve bu değişim sadece radyolojik olarak saptanabilir. Süreç ilerledikçe ve yıkım devam ettikçe diş semptomatik hale geçebilir ve periradiküler abse ile birlikte dişte mobilite artışı da meydana gelebilir. ${ }^{3}$

Eksternal inflamatuar kök rezorpsiyonu genellikle avülsiyon sonrası replantasyon veya lüksasyon yaralanma- 
ları gibi ciddi travmatik yaralanmalar sonucu görülür. Kök yüzeyindeki koruyucu sement tabakasında hasar oluştuğunda yüzeyel rezorpsiyon sonucu alttaki dentin tabakası açığa çıkar ve enfekte dentin tübülleri aracılığıyla kanal içindeki bakteri ve bakteri ürünleri eksternal kök yüzeyine ulaşabilir. Bunun sonucunda klastik hücreler aktive olur ve hem kemikte hem dentinde rezorpsiyona yol açar. ${ }^{4,8}$

Internal rezorpsiyon, kanal duvarının orta ve apikal üçlüsündeki intraradiküler dentin tabakasınde ilerleyen yıkıma neden olan inflamatuar bir durumdur. Rezorbe olan alanlar ya tamamen granulasyon dokusuyla ya da granulasyon dokusuyla beraber sement veya kemik benzeri dokularla kaplanır. ${ }^{9}$ Internal rezorpsiyonu başlatan hücreler pulpal orijinlidir. Genel bulgular rezorpsiyon alanı ile bağlantıı geniş bir aksesuar kanal bulunduğu yönündedir. Bu nedenle bu tip rezorpsiyonların oluşumu ve gelişiminde kollateral kan dolaşımının etkili olduğu belirtilmiştir. ${ }^{4}$ Internal rezorpsiyonu sürdüren diğer durum ise rezorpsiyon alanının apikalinde kalan vital pulpa dokusunun klastik hücrelere kan akımını sağlamasıdır. ${ }^{10}$ Kök rezorpsiyonlarının tedavisinin başarısında rezorpsiyonun tipi, lokasyonu ve boyutu etkilidir. ${ }^{11}$ Tedavide kök kanalının mekanik ve kimyasal dezenfeksiyonu önemlidir. Seans aralarında intrakanal medikamenti olarak $\mathrm{Ca}(\mathrm{OH})_{2}$ kullanılması tavsiye edilmektedir. $\mathrm{Ca}(\mathrm{OH})_{2}$ in güçlü antibakteriyel özelliği, düşük çözünürlüğü sayesinde kanal içinde uzun süreli bir etki oluşturur. Aynı zamanda dentinin $\mathrm{pH}$ ını yükselterek osteoklastik aktivitenin baskılanmasına neden olur. ${ }^{12,13}$

Rezorpsiyon tedavisinde en önemli basamak teşhis ve etkene yönelik tedavi planlamasıdır. Tedavisinde ise günümüzde uygulaması oldukça yaygınlaşan biyouyumlu materyallerle başarılı sonuçlar alınabilmektedir.(14). MTA, biyouyumlu olması ${ }^{15}$, furkasyon perforasyonlar ${ }^{16}$ ve lateral perforasyonların onarımındaki başarıs ${ }^{17}$, periapikal dokular tarafından iyi tolere edilebilir olması ve periodonsiyumda neredeyse tamamen rejenerasyon sağlayabilmesi16 nedeniyle bu tip durumlarda tercih edilmelidir. Aynı zamanda MTA sızdırmazlık açısından da diğer materyallerden üstündür. ${ }^{18}$

Bu vaka raporundaki rezorpsiyon vakalarının hepsinde kanallara temizleme, şeklillendirme ve dezenfeksiyon prosedürleri uygulandıktan sonra kanal dolumu bütünüyle MTA ile yapılmıştır. Tedavi sonrasında alınan radyografiler ile rezorpsiyon vakalarında MTA kullanımının rezorbe dokuların rejenerasyonunda etkili olduğu görülmüştür.

MTA'nın indirekt ultrasonik aktivasyon ile yerleștirilmesinin materyalin fiziksel ve kimyasal özellikleri üzerinde olumlu etkileri olduğuna dair çalışmalar bulunmaktadır. ${ }^{19,20}$ Bu yöntem, aynı zamanda materyalin boşluklara daha iyi yayılmasını ve daha az porözite oluşmasını sağla- maktadır. ${ }^{21}$ Çalışmamızda da MTA indirekt ultrasonik aktivasyon ile yerleştirilmiştir.

İndirekt ultrasonik aktivasyon, rezorpsiyon vakalarında kavitelerin daha iyi doldurulmasına yardımcı olmaktadır. ${ }^{21}$ Ayrıca, apikal kısımda daralımı olmayan rezorbe kanallara veya perforasyon sahalarına MTA yerleştirilirken üzerine direkt bir kondensasyon basıncı uygulanması MTA'nın apikalden taşmasına sebep olabilmektedir. Bunun engellenmesi için kollajen bariyer uygulanması önerilmektedir. ${ }^{22} \mathrm{Bu}$ vaka raporunda da geniş rezorpsiyon sahasına sahip olguda bu sebeple apikalde kollajen bariyer kullanılmıştır.

MTA'nın indirekt ultrasonik aktivasyon metoduyla yerleştirilmesi sayesinde yüksek bir kondensasyon basıncı uygulanmasına gerek kalmadan MTA kanal sınırları içerisinde kalacak şekilde doldurulabilmektedir.

\section{KAYNAKLAR}

1. Locker FG. Hormonal regulation of calcium homeostasis. Nurs Clin North Am 1996; 31: 797-803.

2. Friedman, Shimon, et al. Incidence of external root resorption and esthetic results in 58 bleached pulpless teeth. Dental Traumatology 1988; 4: 23-26.

3. Fuss, Zvi, Igor Tsesis, and Shaul Lin. Root resorptiondiagnosis, classification and treatment choices based on stimulation factors. Dental Traumatology 2003; 19: 175182.

4. Heithersay, G. S. "Management of tooth resorption. Australian Dental Journal 2007; 52.s1: S105-S121.

5. Goldman F, Massone EJ, Esmoris M, Alfie D. Comparison of different techniques for obturating experimental internal resorptive cavities. Endod Dent Traumatol 2000; 16: 116-121.

6. Stamos DE, Stamos DG. A new treatment modality for internal resorption. J Endod 1986; 12: 315-319

7. Torabinejad, Mahmoud, and Ron Lemon. "Use of MTA as Root Perforation Repair." Mineral Trioxide Aggregate: Properties and Clinical Applications 2014; 177-205.

8. Trope M. Root resorption due to dental trauma. Endod Topics 2002; 1: 79-100.

9. Lyroudia KM, Dourou VI, Pantelidou OC, Labrianidis T, Pitas IK. Internal root resorption studied by radiography, stereomicroscope, scanning electron microscope and computerized 3D reconstructive method. Dent Traumatol 2002; 18: 148-152.

10. European Society of Endodontology. Quality guidelines for endodontic treatment: consensus report of the European Society of Endodontology. Int Endod J 2006; 39: 921-930.

11. Ne RF, Witherspoon DE, Gutmann JL. Tooth resorption. Quintessence Int 1999; 30: 9-25.

12. Tronstad, L., et al. pH changes in dental tissues after root canal filling with calcium hydroxide. Journal of End- 
odontics 1981; 7: 17-21.

13. Sjogren U, Figdor D, Spangberg L, Sundqvist G. The antimicrobial effect of calcium hydroxide as a short-term intracanal dressing. Int Endod J 1991; 24: 119-125.

14. Patel, Shanon, et al. Internal root resorption: a review. Journal of endodontics 2010; 36: 1107-1121.

15. Torabinejad M, Hong CU, Pitt Ford TR, Kariyawasam SP. Tissue reaction to implanted Super EBA and Mineral Trioxide Aggregate in the mandible of guinea pigs: a preliminary. J Endod 1995; 21: 569-571.

16. Regan JD, Gutmann JL, Witherspoon DE. Comparison of Diaket and MTA when used as root-end filling materials to support regeneration of the periradicular tissues. Int Endod J 2002; 35: 840-847.

17. Main C, Mirzayan N, Shabahang S, Torabinejad M. Repair of root perforations using mineral trioxide aggregate: a long term study. J Endod 2004; 30: 80-83.

18. Jacobovitz M, Vianna ME, Pandolfelli VC, Oliveira IR, Rossetto HL, Gomes BP. Root canal filling with cements based on mineral aggregates: an in vitro analysis of bacterial microleakage. Oral Surg Oral Med Oral Pathol Oral Radiol Endod 2009;108: 140-144.

19. Basturk FB, Nekoofar MH, Günday M, Dummer PM. The effect of various mixing and placement techniques on the compressive strength of mineral trioxide aggregate. Journal of endodontics. 2013; 39: 111-114.

20. Basturk FB, Nekoofar MH, Gunday M, Dummer PM. Effect of various mixing and placement techniques on the flexural strength and porosity of mineral trioxide aggregate. Journal of endodontics. 2014; 40: 441-445.

21. Yeung $P$, Liewehr FR, Moon PC. A quantitative comparison of the fill density of MTA produced by two placement techniques. Journal of endodontics. 2006; 32: 456459.

22. Ferris DM, Baumgartner JC. Perforation repair comparing two types of mineral trioxide aggregate. Journal of endodontics. 2004; 30: 422-424. 
